\title{
STRATEGI PENGEMBANGAN AGROWISATA DI PERKEBUNAN KOPI GAYO DESA GUNUNG SUKU KABUPATEN ACEH TENGAH
}

\author{
Oleh \\ Ihyana Hulfa'), Ander Sriwi' ${ }^{2)}$ \& Rizal Kurniansah ${ }^{3)}$ \\ ${ }^{123}$ Sekolah Tinggi Pariwisata Mataram \\ Email: 1. 1hyana_hulfa@yahoo.com, 2andar26semilarity@gmail.com \& \\ rizalkurniansah@gmail.com
}

\begin{abstract}
Gunung Suku Village has a natural, social cultural appeal that is very diverse and potentially become a tourist attraction, but this potential tourism has not been developed well and maximal to becomes a tourist destination. This study aims to formulate effective strategies for the development of agrotourism in Gunung Suku Village. This study uses qualitative methods, data collection through observation, in-depth interviews, questionnaires and literature study. Purposive sampling used in this study for determination of sample, Data analysis in this study used qualitative descriptive approach, IFAS, EFAS and SWOT analysis. The results of this study indicate the potential of coffee plantation areas has not been developed, due to the lack of human resources, accessibility, facilities and infrastructure of tourism activities and the weak role of local government. The general strategy is in quadrant II, namely the development strategy of attractiveness. Alternative strategies (1) SO strategies (a) Strategies for developing potential to the fullest, (b) Strategies for developing marketing and promoting tourist attraction, (c) Development strategies for making tour packages. (2) ST Strategy (a) Community-based agrotourism development strategy, (b) Development Strategy by highlighting different potentials from other regions. (3) WO Strategy (a) HR development strategies especially in the field of tourism, (b) Accessibility development strategies, (c) Strategies to develop places to stay, eat drinks and gift shops. (4) WT Strategy (a) Increasing Public Awareness to conserve and preserve local culture, as well as the emergence of many competitors, (b) Increase cooperation with all stakeholders, (c) Improve the development of human recources in the tourms sector. Agrotourism development requires cooperation with all stakeholders in order to improve the qualityof human resources, accessibility, facilities and institutions, so that it has a direct impact on the income of the villagers of Gunung Suku Village.
\end{abstract}

Keywords: Potential, Agrotourism \& Development Strategy.

\section{PENDAHULUAN}

Desa Gunung Suku berda di Kabupaten Aceh Tengah Provinsi Aceh. Berjarak sekitar $13 \mathrm{Km}$ dari pusat Kota Takegon dan berada tepat di pinggir Danau Laut Tawar yang menjadi prioritas pengembangan pariwisata Kabupaten Aceh tengah. Desa Gunung Suku memiliki potensi alam, sosial budaya dan butatan yang sangat beragam dan potensial untuk dikembangkan. Salah satunya adalah hamparan perkebunan kopi yang tumbuh subur, memiliki citra yang mendunia dan gread yang baik. Selain itu budaya dalam perkebunan kopi seperti menggunakan mantra Siti Kewe yang membuatnya berbeda dengan Perkebunan Kopi llainya di Indonesia. Menjadi petani kopi bukanlah halyang tidak membanggakan di Takengon. Kopi telah menjadi budaya dan sangat melekat dengan masyarakat Suku Gayo 90 persen masyarakat memiliki perkebunan kopi dengan bermacam-macam latar belakang, dari petinggi daerah sampai masyrakat biasa, perbedaannya hanya luas lahan yang dimiliki saja.

Bermodalkan keberanian dan keinginan kuat kuat dan potensi yang ada pemuda desa 
memberanikan diri untuk menyelenggarakan kegiatan "Festival Panen Kopi" pada tanggal 16-17 Desember 2017 dengan harapan kegiatan ini dapat mempromosikan desa sehingga mendatangkan banyak wisatawan, sehingga memberikan peluang kerja bagi masyarakat. Potensi yang ada dan usaha masyarakat untuk mengembangkan desa belumlah cukup untuk menjadikan Desa Gunung Suku sebagai sebuah destinasi wisata. Hingga saat ini, kunjungan wisatawan hanya pada saat kegiatan Festival Panen Kopi 2017 saja. Padahal desa ini berdekatan dengan destiansi wisata Danau Laut Tawar yang banyak dikunjungi wisatawan lokal pada hari libur. Berdasarkan permasalahan yang dipaparkan sebelumnya, penulis tertarik dan merasa penting untuk meneliti mengenai Pengembangan Kawasan Perkebunan Kopi Sebagai Agrowisata Desa Gunung Suku Kabupaten Aceh Tengah.

\section{LANDASAN TEORI}

Penelitian ini menggunakan teori pengembangan pariwisata pengembangan pariwisata. Pertama Menurut Yoeti (1991) menyatatakan ada beberapa aspek yang perlu diketahui dalam perencanaan pariwisata adalah: (1) tourist, (2) transportations, (3) Attractions, (4) Service Facilities, (5) Informations. Kedua teori perencanaan strategis menurut Rangkuti (2006) perencanaan strategis adalah kegiatan organisasi mencari kesesuaian antara kekuatan-kekuatan internal (kekuatan dan kelemahan) dan kekuatankekuatan eksternal (peluang dan ancaman) suatu pasar.kegiatan meliputi pengamatansecara hati-hati terhadap persaingan, peraturan tingkat inflasi, siklus bisnis, keinginan dan harapan konsumen serta faktor-faktor lain yang dapat megidentifikasi peluang dan ancaman, sehingga memerlukan tiga tahap analisis yaitu (1) Tahapan pengumpulan data, (2) Tahap analisis, (3) Tahap pengambilan keputusan. Teori tersebut digunakan untuk menentukan komponen dan tahapan yang harus direncanakan guna pengembangan potensi perkebunan Kopi Gayo menjadi agrowisata di Desa Gunung Suku.

\section{METODE PENELITIAN}

Penelitian ini menggunakan pendekatan deskriptif kualitatif, adapun Jenis data berupa kualitatif dan kuantitatif bersumber dari data primer dan sekunder. Instrumen dalam penelitian ini adalah peneliti sendiri, alat tulis, kamera/handphone untuk mendokumentasikan gambar-gambar lokasi penelitian serta sebagai alat merekam wawancara, pedoman wawancara dipergunakan agar arah pembicaraan bisa lebih terfokus, kuesioner dengan beberapa pilihan jawaban yang telah disediakan. Teknik penentuan informan dan responden secara purposive sampling dimana informan dan responden ditentukan secara sengaja berdasarkan masksut dan tujuan tertentu dan benar-benar mengetahui dan kompeten mengenai kondisi internal dan eksternal data kepariwisataan khusunya Desa Gunung Suku, agar informasi atau keterangan yang diberikan dapat lebih di pertanggungjawabkan. Pengumpulan data dilakukan dengan studi pustaka, observasi, wawancara mendalam kepada 11 orang informan, dan penyebaran kuesioner kepada 14 orang responden guna memberikan bobot dan rating masing-masing faktor internal dan eksternal.

Penelitian ini menggunakan teknik analisis, analisis IFAS dan EFAS dan SWOT untuk dapat menghasilkan strategi umum (grand strategy ) dan strategi altenatif (alternative strategy) dalam pengembangan kawasan perkebunan Kopi Gayo sebagai agrowisata. Hasil analisis data tersebut disajikan secara formal dalam bentuk foto, gambar serta tabel dan secara informal yaitu dalam bentuk narasi.

\section{HASIL DAN PEMBAHASAN \\ Potensi dan Daya Tarik Wisata Desa Gunung Suku}

Desa Gunung Suku memiliki potensi daya tarik wisata yang beragam seperti, air terjun, Gua Daulat Aceh, Masjid Baiturrahim, budaya dalam perkebunan kopi, kearifan lokal, budaya membuat tembakau, lanskap yang indah dan udara yang sejuk, budaya kejurun 
belang, budaya tulak bele, Didong, Tari Guel, Becanang. Potensi tersebut belum dikembangkan menjadi sebuah atraksi wisata, hal tersebut terjadi karena minimnya SDM khususnya di bidang pariwisata, aksesibilitas, fasilitas pariwisata yang kurang memadai serta kelembagaan.

\section{Analisis Matrik IFAS dan EFAS}

Desa Gunung suku memiliki faktorfaktor kekuatan dan kelemahan pada masingmasing lingkungan internal dan eksternal, faktor-faktor tersebut kemudian diberikan bobot dan rating sehingga menghasilkan skor pada masing-masing indikator kekuatan dan kelemahan, data tersebut secara lebih terperinci dapat dilihat pada Tabel 3.1 dan 4.2.

Tabel 1. Matriks IFAS Perkebunan Kopi Gayo di Desa Gunung Suku

\begin{tabular}{|c|c|c|c|c|}
\hline No & $\begin{array}{ll}\text { Faktor-faktor } & \text { Strategi } \\
\text { Internal } & \\
\end{array}$ & Bobot & Rating & Skor \\
\hline \multicolumn{5}{|c|}{ Kekuatan (Strengths) } \\
\hline 1 & $\begin{array}{l}\text { Potensi sumber daya alam dan } \\
\text { buatan }\end{array}$ & 0.076 & 3.93 & 0.299 \\
\hline 2 & $\begin{array}{l}\text { Budaya dalam perkebunan } \\
\text { kopi yang unik }\end{array}$ & 0.065 & 3.57 & 0.232 \\
\hline 3 & $\begin{array}{l}\text { Bentang alam yang indah } \\
\text { serta udara yang } \\
\text { Sejuk }\end{array}$ & 0.063 & 3.71 & 0.234 \\
\hline 4 & Partisipasi masyarakat & 0.058 & 3.14 & 0.182 \\
\hline 5 & $\begin{array}{lll}\text { Citra Kopi } & \text { Gayo yang } \\
\text { mendunia }\end{array}$ & 0.033 & 3.36 & 0.111 \\
\hline 6 & Lokasi dekat Kota Takengon & 0.051 & 3.29 & 0.168 \\
\hline 7 & $\begin{array}{lll}\text { Keamanan Desa Gunung } \\
\text { Suku }\end{array}$ & 0.032 & 3.64 & 0.116 \\
\hline \multicolumn{5}{|c|}{ Kelemahan (Weaknesses) } \\
\hline 1 & $\begin{array}{l}\text { Akses menuju Desa Gunung } \\
\text { Suku yang masih } \\
\text { kurang memadai }\end{array}$ & 0.074 & 2.93 & 0.217 \\
\hline 2 & $\begin{array}{l}\text { Tidak tersedianya } \\
\text { trasnportasi umum }\end{array}$ & 0.059 & 2.29 & 0.135 \\
\hline 3 & $\begin{array}{l}\text { Tidak tersedianya sumber } \\
\text { informasi }\end{array}$ & 0.071 & 1.93 & 0.137 \\
\hline 4 & $\begin{array}{l}\text { Tidak tersedianya tempat } \\
\text { makan dan minum }\end{array}$ & 0.069 & 1.86 & 0.128 \\
\hline 5 & $\begin{array}{l}\text { Tidak tersedianya toko } \\
\text { cinderamata }\end{array}$ & 0.063 & 1.57 & 0.099 \\
\hline 6 & $\begin{array}{l}\text { Lemahnya kualitas SDM di } \\
\text { bidang pariwisata }\end{array}$ & 0.087 & 2.71 & 0.236 \\
\hline 7 & $\begin{array}{ll}\text { Kurangnya } & \text { keterlibatan } \\
\text { Stakeholders } & \end{array}$ & 0.073 & 2.57 & 0.188 \\
\hline 8 & $\begin{array}{l}\text { Rendahnya kesadaran } \\
\text { masyarakat terhadap } \\
\text { kebersihan lingkungan }\end{array}$ & 0.046 & 2.64 & 0.121 \\
\hline \multirow[t]{2}{*}{9} & $\begin{array}{l}\text { Kegiatan wisata yang belum } \\
\text { tersruktur dan } \\
\text { Memadai }\end{array}$ & 0.080 & 2.43 & 0.194 \\
\hline & TOTAL & 1.00 & - & 2.797 \\
\hline
\end{tabular}

Sumber: Hasil Penelitian, 2018

Berdasarkan data Tabel 4.1 menunjukan bahwa indikator kekuatan yang mendapat skor tertinggi yaitu potensi sumber daya alam dan buatan sebesar 0.299, sedangkan indikator kekuatan yang mendapat skor paling rendah adalah citra kopi yang mendunia dengan total skor 0,111. Faktor kelemahan dalam lingkungan internal yang mendapat skor tertinggi adalah lemahnya sumber daya manusia dengan total skor adalah 0.236 , dan yang paling rendah adalah tidak tersedianya toko cindra mata dengan skor 0.099. Total bobot pada faktor lingkungan internal adalah 1, dan total skor sebesar 2,797.

Tabel 2. Matriks EFAS Perkebunan Kopi Gayo di Desa Gunung Suku

\begin{tabular}{|c|c|c|c|c|}
\hline No & $\begin{array}{l}\text { Faktor-faktor Strategi } \\
\text { Internal }\end{array}$ & Bobot & Rating & Skor \\
\hline \multicolumn{5}{|c|}{ Peluang (Opportunitis) } \\
\hline 1 & $\begin{array}{l}\text { Berada pada daerah } \\
\text { prioritas } \\
\text { pengembangan pariwisata } \\
\text { Aceh }\end{array}$ & 0.121 & 3.93 & 0.476 \\
\hline 2 & $\begin{array}{l}\text { Berada dekat dengan } \\
\text { Danau Laut Tawar } \\
\text { sebagai prioritas } \\
\text { pengembangan } \\
\text { pariwisata Aceh Tengah }\end{array}$ & 0.152 & 3.79 & 0.576 \\
\hline 3 & $\begin{array}{l}\text { Tran pariwisata alternatif } \\
\text { (Agrowisata) }\end{array}$ & 0.082 & 3.36 & 0.276 \\
\hline 4 & $\begin{array}{l}\text { Kemajuan teknologi } \\
\text { informasi dan } \\
\text { Telekomunikasi }\end{array}$ & 0.144 & 3.57 & 0.514 \\
\hline 5 & $\begin{array}{ll}\text { Minat } & \text { berwisata } \\
\text { masyarakat } & \end{array}$ & 0.104 & 3.71 & 0.386 \\
\hline 6 & $\begin{array}{l}\begin{array}{l}\text { Peningkatan kerjasama } \\
\text { dengan seluruh }\end{array} \\
\text { Stakeholders }\end{array}$ & 0.147 & 2.79 & 0.410 \\
\hline \multicolumn{5}{|c|}{ Ancaman (Threats) } \\
\hline 1 & $\begin{array}{l}\text { Perubahan iklim secara } \\
\text { drastis serta } \\
\text { curah hujan yang tinggi }\end{array}$ & 0.063 & 1.86 & 0.117 \\
\hline 2 & $\begin{array}{l}\text { Masuknya budaya luar } \\
\text { yang mengikis } \\
\text { budaya lokal }\end{array}$ & 0.095 & 2.43 & 0.231 \\
\hline 3 & $\begin{array}{l}\text { Penilaian bekas daerah } \\
\text { konflik yang tidak } \\
\text { Aman }\end{array}$ & 0.018 & 2.86 & 0.051 \\
\hline \multirow[t]{2}{*}{4} & $\begin{array}{l}\text { Munculnya kompetitor } \\
\text { baru }\end{array}$ & 0.075 & 1.50 & 0.113 \\
\hline & TOTAL & 1.00 & - & 3.149 \\
\hline
\end{tabular}

Sumber: Hasil penelitian, 2018

Berdasarkan data pada tabel 4.2 tersebut menunjukkan indikator peluang yang mendapatkan skor tertinggi adalah Berada dekat dengan Danau Laut Tawar sebagai 
prioritas pengembangan pariwisata Aceh Tengah sebesar 0,575, sedangkan indikator peluang yang mendapatkan skor terendah adalah Tran pariwisata alternatif (Agrowisata) sebesar 0.276, sedangkan ancaman dari lingkungan eksternal yang mendapat skor tetinggi adalah masuknya budaya luar yang mengikis budaya lokal dengan skor 0.231 dan yang paling rendah adalah penilain bekas daerah konflik yang tidak aman dengan skor 0.051. Total bobot bobot pada faktor lingkungan eksternal adalah 1, dan total skor sebesar 3,149.

Setelah mengetahui jumlah skor IFAS sebesar 2,797 dan skor EFAS sebesar 3,149 maka dapat diketahui posisi strategis daya tarik perkebunan Kopi Gayo di Desa Gunung Suku dalam kuadran SWOT, seperti yang disajikan pada Tabel 4.3.

Tabel 3. Matriks Internal-Eksternal Posisi Strategis Pengembangan Perkebunan Kopi Gayo Sebagai Agrowisata Desa Gunung Suku Kabupaten Aceh Tengah

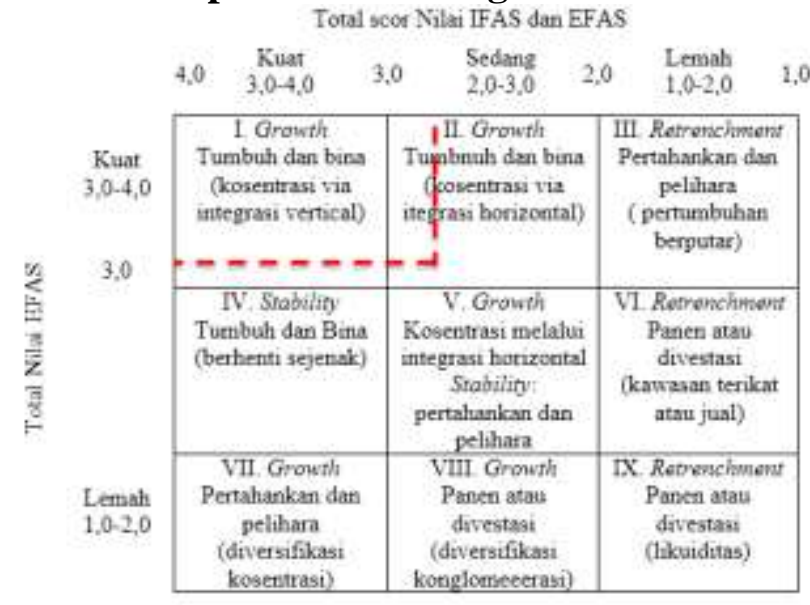

Sumber: Hasil analisis data IFAS dan IFAS

Berdasarkan Gambar 4.1 tersebut, menunjukkan posisi pengembangan kawasan perkebunan Kopi Gayo di Desa Gunung Suku berada pada Kuadran II, yaitu Growth Startegy (Startegi Pertumbuhan) yang merupakan pertumbuhan pengembangan potensi dan daya tarik iu sendiri atau diversifikasi. Strategi umum pengembangan kawasan perkebunan Kopi Gayo adalah mengembangkan potensi wisata secara maksimal, menambahkan kualitas produk wisata dan pelayanan masyarakat, melakukan promosi dengan target pasar yang lebih luas, menonjolkan potensi yang unik dan berbeda dari perkebunan kopi lain sehingga memiliki daya saing yang tinggi. Sehingga pengembangan sesui tujuan dan dapat berdampak pada pendapatan masyarakat Desa Gunung Suku.

\section{Analisis SWOT}

Setelah mengetahui posisi strategis kawasan perkebunan Kopi Gayo di Desa Gunung Suku maka dapat disusun strategi alternatif dalam bentuk Matriks SWOT. Matriks SWOT secara lebih jelas dapat dilihat pada Tabel 4.

\section{Tabel 4. Matrik SWOT}

\begin{tabular}{|c|c|c|}
\hline EFAS & $\begin{array}{l}\text { STRENGTHS } \\
\text { (S) } \\
\text { 1. Potensi } \\
\text { sumber } \\
\text { daya alam } \\
\text { dan buatan } \\
\text { 2. } \begin{array}{l}\text { Budaya } \\
\text { dalam } \\
\text { perkebunan }\end{array} \\
\text { kopi yang } \\
\text { unik } \\
\text { 3. Bentang } \\
\text { alam yang } \\
\text { indah serta } \\
\text { udara yang } \\
\text { sejuk } \\
\text { 4. Partisipasi } \\
\text { masyarakat } \\
\text { 5. Citra Kopi } \\
\text { Gayo yang } \\
\text { mendunia } \\
\text { Lokasi } \\
\text { dekat Kota } \\
\text { Takengon } \\
\text { Keamanan } \\
\text { Desa } \\
\text { Gunung } \\
\text { Suku }\end{array}$ & 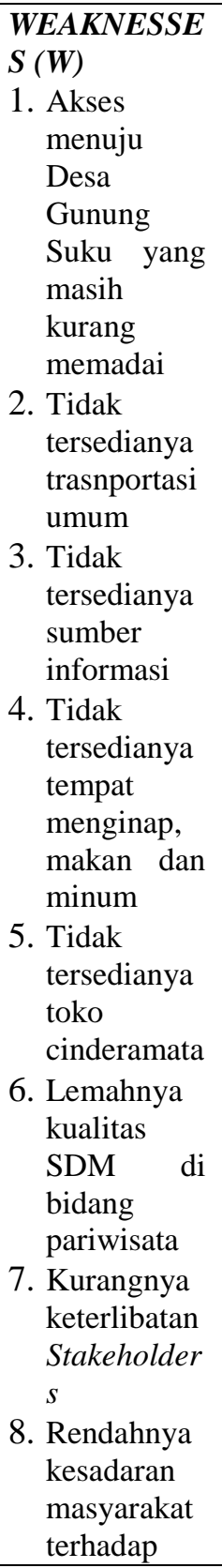 \\
\hline
\end{tabular}




\begin{tabular}{|c|c|c|}
\hline & & $\begin{array}{l}\text { kebersihan } \\
\text { lingkungan } \\
\text { 9. Kegiatan } \\
\text { wisata yang } \\
\text { belum } \\
\text { tersruktur } \\
\text { dan } \\
\text { memadai }\end{array}$ \\
\hline $\begin{array}{ll}\text { OPPORTUNI } \\
\text { TIES }(\boldsymbol{O}) \\
\text { 1. } & \text { Berada } \\
\text { pada } \\
\text { daerah } \\
\text { prioritas } \\
\text { pengemba } \\
\text { ngan } \\
\text { pariwisata } \\
\text { Aceh } \\
\text { 2. } \\
\text { Berada } \\
\text { dekat } \\
\text { dengan } \\
\text { Danau } \\
\text { Laut } \\
\text { Tawar } \\
\text { sebagai } \\
\text { prioritas } \\
\text { pengemba } \\
\text { ngan } \\
\text { pariwisata } \\
\text { Aceh } \\
\text { Tengah } \\
\text { Tran } \\
\text { pariwisata } \\
\text { alternatif } \\
\text { (Agrowisa } \\
\text { ta) } \\
\text { Kemajuan } \\
\text { teknologi } \\
\text { informasi } \\
\text { dan } \\
\text { telekomun } \\
\text { ikasi } \\
\text { Minat } \\
\text { berwisata } \\
\text { masyaraka } \\
\text { t } \\
\text { 6. Peningkata } \\
\text { n } \\
\text { kerjasama } \\
\text { dengan } \\
\text { seluruh } \\
\text { stakeholde } \\
\text { rs } \\
\text { 5. }\end{array}$ & $\begin{array}{l}\text { STRATEGI } \\
\text { SO } \\
\text { 1. Strategi } \\
\text { pengemban } \\
\text { gan potensi } \\
\text { dan daya } \\
\text { tarik yang } \\
\text { dimiliki } \\
\text { (S1, S2, S3; } \\
\text { O2, O3, } \\
\text { O4, O5) } \\
\text { 2. Stategi } \\
\text { pengemban } \\
\text { ganp } \\
\text { pemasaran } \\
\text { dan } \\
\text { promosi } \\
\text { daya tarik } \\
\text { wisata. } \\
\text { (S1-S7; O4, } \\
\text { O6) } \\
\text { 3. Strategi } \\
\text { Pengemban } \\
\text { gan dengan } \\
\text { bembuat } \\
\text { paket } \\
\text { wisata } \\
\text { (S1-S7; O3, } \\
\text { O4, O5) }\end{array}$ & $\begin{array}{l}\text { STRATEGI } \\
\text { WO } \\
\text { 1. } \\
\text { Strategi } \\
\text { pengemba } \\
\text { ngan SDM } \\
\text { khususnya } \\
\text { dibidang } \\
\text { pariwisata } \\
\text { (W3, W4, } \\
\text { W5, W6, } \\
\text { W8, W9; } \\
\text { O4, O6) } \\
\text { 2. Strategi } \\
\text { pengemba } \\
\text { ngan } \\
\text { aksesibilit } \\
\text { as } \\
\text { (W1, W2; } \\
\text { O1, O2, } \\
\text { O6) } \\
\text { 3. Strategi } \\
\text { pengemba } \\
\text { ngan } \\
\text { tempat } \\
\text { menginap, } \\
\text { makan } \\
\text { minum } \\
\text { dan toko } \\
\text { oleh-oleh } \\
\text { (W4, W5; } \\
\text { O1, O2, } \\
\text { O4, O6) }\end{array}$ \\
\hline $\begin{array}{l}\text { THREATS }(\text { T) } \\
\text { 1. Perubahan } \\
\text { iklim } \\
\text { secara }\end{array}$ & $\begin{array}{l}\text { STRATEGI } \\
\text { ST } \\
\text { 1. Strategi } \\
\text { pengemban }\end{array}$ & $\begin{array}{l}\text { STRATEGI } \\
\text { WT }\end{array}$ \\
\hline
\end{tabular}

\begin{tabular}{|c|c|c|}
\hline $\begin{array}{l}\text { drastis } \\
\text { serta } \\
\text { Curah } \\
\text { hujan yang } \\
\text { tinggi } \\
\text { 2. Masuknya } \\
\text { budaya } \\
\text { luar yang } \\
\text { mengikis } \\
\text { budaya } \\
\text { lokal } \\
\text { 3. Penilaian } \\
\text { bekas } \\
\text { daerah } \\
\text { konflik } \\
\text { yang tidak } \\
\text { aman } \\
\text { 4. Munculny } \\
\text { a } \\
\text { kompetitor } \\
\text { baru }\end{array}$ & $\begin{array}{l}\text { gan } \\
\text { agrowisata } \\
\text { berbasis } \\
\text { masyarakat } \\
\text { ( } 1, \mathrm{~S} 2, \mathrm{~S} 3, \\
\text { S4, S7; W2, } \\
\text { W4) } \\
\text { 2. Strategi } \\
\text { Pengemban } \\
\text { gan dengan } \\
\text { menonjolka } \\
\text { n potensi } \\
\text { yang } \\
\text { berbeda } \\
\text { dari daerah } \\
\text { lainya. } \\
\text { (S1, S2, S3, } \\
\text { S5; W4) }\end{array}$ & $\begin{array}{l}\text { 1. Meningkat } \\
\text { kan } \\
\text { Kesadaran } \\
\text { Masyarak } \\
\text { at untuk } \\
\text { menjaga } \\
\text { dan } \\
\text { melastarik } \\
\text { an budaya } \\
\text { lokal, serta } \\
\text { munculny } \\
\text { a banyak } \\
\text { kompetito } \\
\text { r. } \\
\text { (W8; T2, } \\
\text { T4) } \\
\text { Meningkat } \\
\text { kan kerja } \\
\text { sama } \\
\text { dengan } \\
\text { seluruh } \\
\text { Srakehold } \\
\text { ers. } \\
\text { (W7; T4) } \\
\text { Meningkat } \\
\text { kan } \\
\text { pengemba } \\
\text { ngan } \\
\text { sumber } \\
\text { daya } \\
\text { manusia } \\
\text { dibidang } \\
\text { pariwisata } \\
\text { (W3, W4, } \\
\text { W5, W6, } \\
\text { W7, W8, } \\
\text { W9; T1, } \\
\text { T2, T3, } \\
\text { T4) }\end{array}$ \\
\hline
\end{tabular}

Sumber: Hasil penelitian, 2018

Berdasarkan empat sel mastrik SWOT pada Tabel 3.3 tersebut, maka dapat dirumuskan beberapa strategi altenatif pengembangan Kawasan Perkebunan Kopi Gayo di Desa Gunung Suku Kabupaten Aceh Tengah, sebagai berikut:

1. Strategi SO (Strengths Opportunity)

Strategi SO merupakan strategi yang menanfaatkan seluruh kekuatan untuk merebut dan memanfaatkan seluruh peluang yang dimiliki secara maksimal, seperti berikut ini:

a. Strategi pengembangan potensi secara maksimal. 
Pengembangan potensi secara maksimal, dimana segala potensi yang ada di Desa Gunung Suku berupa kekayaan alam, sosial dan budaya dijadikan sebuah atraksi wisata. Berdasarkan strategi tersebut dapat dilakukan beberapa program sebagai berikut:

1. Membangun akses jalan setapak, yang dapat dilakukan secara gotong royong dengan seluruh masyarakat.

2. Menambah aktifitas di daya tarik wisata, seperti membentuk jalur tracking menuju air terjun, gua Loyang Daulat dan perkebunan kopi. Daya tarik wisata yang dimiliki tidak hanya sebagai tempat untuk berfoto, melainkan sebagai tempat edukasi bagi wisatawan, meliputi perkebunan kopi, Masjid Baiturrahim dan Loyang Daulat Aceh yang memiliki nilai sejarah dan budaya

b. Strategi pengembangan pemasaran dan promosi daya tarik wisata.

Pemasaran adalah suatu proses mulai dari perencanaan suatu konsep, penentuan harga, dan pelaksanaan ide agar dapat menentukan segmen, target pasar dan promosi dalam pengembangan agrowisata berbasis masyarakat di Desa Gunung Suku. Berdasarkan strategi tersebut dapat dilakukan beberapa program sebagai berikut:

1. Menentukan siapa target pasar pengembangan seperti apakah pengembangan tersebut untuk wisatawan individu, instansi, swasta, komunitas tertetentu, anak-anak orang dewasa sehingga pengembangan dapat mencapai dan sesuai dengan target pasar.

2. Program promosi, promosi adalah salah satu cara untuk mengenalkan atau menawarkan produk wisata yang dimiliki kepada calon wisatawan. Promosi dapat dilakukan melalui media cetak dan elektronik.

c. Strategi pengembangan dengan bembuat paket wisata

Pengembangan kawasan perkebunan Kopi Gayo di Desa Gunung Suku dapat dilakukan dengan membuat paket wisata. Berdasarkan strategi tersebut maka dapat dilakukan beberapa program sebagai berikut ini:

1. Membuat paket Half day tour paket tur wisata singkat selama 6 jam, dimana wisatawan dapat memilih atraksi yang ditawarkan, seperti tracking air terjun, Loyang Daulat dan berinterkasi langsung dengan petani kopi yang memeberikan edukasi di dalam perkebuna kopi dan mendapatkan makan 1 kali makan siang, tur ini dapat di mulai pada pagi hari.

2. Membuat paket Full Day Tour adalah tur yang ditawarkan kepada wisatawan selama 1 hari atau 12 jam, dimana wisatawan dapat mengunjungi daya tarik wisata yang ada di Desa Gunung Suku dan mendapatkan 1 kali makan siang dan malam yang dipandu oleh masyarakat lokal.

3. Membuat paket One Day Tour dimana wisatawan akan menginap di rumah masyarakat sehingga dapat mempelajari dan berbagi dan merasakan langsung budaya lokal.

2. Strategi ST (Strengths Threats)

Strategi Pengembangan dengan menonjolkan potensi yang berbeda dari daerah lainya.

Agrowisata kopi di Kabupaten Aceh Tengah sudah mulai banyak dikembangkan oleh petani kopi, budaya menanan pada kopi, budaya kejurun belang, didong, keindahan alam dan kearifan lokal, seperti nelayan, proses pembuatan tembakau, penjemuran ikan depik dan lainya secara umum dapat ditemui di Kabupaten Aceh Tengah namun, tidak berada pada satu kawasan. Keunggulan Desa Gunung Suku adalah, segala potensi tersebut berada dalam satu kawasan. Program yang dapat dilakukan adalah memaksimalakan pengembangan Masjid Baiturahim dan Loyang Daulat yang memiliki nilai sejarah dan budaya, dikemas sedemikian rupa sehingga memiliki nilai historikal yang tinggi. 
3. Strategi WO (Weaknesses Opportunity)

a. Strategi pengembangan SDM khususnya dibidang pariwisata

Sumber daya manusia merupakan unsur penting dalam pengembangan pariwisata, pariwisata tidak terlepas dari sebuah perdagangan jasa yang ditawarkan kepada wisatawan. Sumber daya manusia sangat terkait dengan kegiatan pariwisata, dimana berbagai kegiatan wisata yang didukung berbagai fasilitas serta layanan yang disediakan oleh masyarakat langsung, dengan dukungan dari pemerintah dan pengusaha. Masyarakat Desa Gunung Suku adalah sebagai tuan rumah atau host yang memberikan pelayanan langsung kepada wisatawan. Hal ini menuntut masyarakat untuk memiliki kemampuan dan pengetahuan dalam bidang pariwisata agar memberikan pelayanan yang priama dalam memenuhi segala kebutuhan wisatatan. Sehingga perlu dilakukan program sebagai berikut:

1. Melakukan kerjasama dengan seluruh stakeholders untuk mengembangkan pengetahuan dan kualitas SDM khsususnya di bidang pariwisata yang ada di Desa Gunung Suku, baik itu dari masyarakat dengan pemerintah daerah maupun dengan swata.

2. penyuluhan yang dilakukan dinas terkait dan swasta mengenai kegiatan wisata untuk menumbuhkan kesadara seluruh komponen masyarakat mengenai perannya sebagai tuan rumah, untuk menerapkan dan menciptakan sapta pesona yang di dalamnya yang didalamnya terdapat unsur aman, tertib, bersih, sejuk, indah, ramah dan kenangan, merupakan unsur penting dalam pariwisata.

3. Pembentukan kelompok sadar wisata (POKDARWIS) Desa Gunung Suku. POKDARWIS merupakan sebuah organisasi atau kelompok ditingkat masyarakat yang berperan aktif dalam pengembangan pariwisata desa tersebut, sehingga terciptanya sapta pesona dalam meningkatkan pembangunan dan pendapatan masyarakat Desa Gunung Suku khusunya dari industri pariwisata.

b. Strategi pengembangan aksesibilitas

Aksesibilitas menyangkut sarana dan infrastruktur yang digunakan wisatawan, yang meliputi jalan raya, transportasi, rambu-rambu penunjuk jalan dan jalan setapak yang merupakan unsur penting di sebuah destinasi wisata. Desa Gunung Suku memiliki daya tarik wisata yang sangat berpotensial untuk dikembangkan. Memeliki potensi yang menarik belum cukup untuk menarik minat wisatawan. Berdasarkan stratgi tersebut maka dapat dilakukan beberapa program sebagai berikut:

1. Membangun kerja sama dengan seluruh pemangku kepentingan, khususnya pihak pemerintah, dinas perhubungan dan dan Dinas Pembangunan Daerah, khususnya dalam pembangunan infrastruktur jalan yang kurang memadai, serta ketersedian trasportasi untuk menjangkau desa, dari pusat Kota Takengon menuju Desa Gunung Suku, serta pembangunan pusat informasi mengenai daya Tarik wisata desa gunung suku yang dapat dikelola langsung oleh masyarakat yang telah diberikan pelatihan.

2. Pengembangan jalan setapak yang dapat dilakukan oleh masyarakat guna memberikan kemudahan dan kenyaman bagi wisatawan yang berkunjung dalam menikmati agrowisata kawasan perkebunan kopi seperti yang telah dipaparkan sebelumnya.

c. Strategi pengembangan tempat menginap, makan minum dan toko oleh-oleh.

Desa Gunung Suku belum memiliki tempat menginap, makan minum dan oleh-oleh yang memadai. Tempat menginap, makan minum dan toko oleh-oleh merupakan fasilitas pendukung pengembangan pariwisata. ketersedian fasilitas tersebut dapat memenuhi dan memberikan kenyamanan bagi wisatawan. Berdasarkan strategi tersebut maka dapat dilakukan program sebagai berikut: 
1. Pengembangan fasilitas tersebut dilakukan dengan konsep pengembangan pariwisata perdesaan. Dimana penginapan yang disediakan adalah homestay.

2. Pengembangan rumah makan dan minum yang dibangun di seputar perkebunan kopi, sehingga wisatawan dapat beristirahat dan menikmati makan dan minum khas masyarakat Gayo yang disajikan langsung oleh masyarakat.

3. Pembangunan ruang untuk menjual souvenir, baik hasil tani yang telah dikemas sebagai produk wisata yang menarik dan memiliki nilai jual.

4. Strategi WT (Weaknesses Threats)

a. Meningkatkan Kesadaran Masyarakat untuk menjaga dan melastarikan budaya lokal, serta munculnya banyak kompetitor. Berdasarkan strategi tersebut maka dapat dilakukan program. Penyuluhan, membangun tempat pengolahan limbah serta menyediakan tempat pembuangan sampah, penyedian tempat sampah tersebut dapat dilakun masyarakat dengan menggunakan bambu yang ada di perkebunan mereka membuat anyaman yang berbentuk keranjang sampah.

b. Meningkatkan kerja sama dengan seluruh Stakeholders.

Berdasarkan strategi tersebut maka program yang dapat dilakukan adalah,

1. Membentuk badan koprasi simpan pinjam yang bekerja sama dengan pemerintah sehingga hasil dari kegiatan wisata dapat dikelola dengan baik dan berdampak secara merata kepada seluruh masyarakat.

2. Pemerintah memberikan modal dalam pengembangan pariwisata, seperti pembangunan toko souvenir, pelatihan cara mengemas produk oleh-oleh yang memiliki daya jual yang baik.

c. Meningkatkan pengembangan sumber daya manusia dibidang pariwisata

Bedasarkan strategi tersebut maka program yang dapat dilakukan adalah:
1. Meningkatkan pelatihan dan penyuluhan yang dilakukan secara berkesinambungan serta melakukan pendampingan kepada masyarakat desa Gunung Suku dalam mengembangkan pariwisata khususnya agrowisata berbasis masyarakat yang efektif.

2. Kerja sama dengan pemerintah dan swasta dapat ditingkatkan khususnya yang berkaitan dengan pengembangan SDM dan penerapan konsep sadar wisata kepada seluruh masyarakat Desa Gunung Suku.

\section{PENUTUP}

\section{Kesimpulan}

Kesimpulan dari hasil pembahasan dan analisis maka dapat disimpulkan bahwa potensi alam dan sosial budaya Desa Gunung Suku sangat beragam dan berpotensial untuk dikembangan sebagai agrowisata. Startegi umum pengembangan kawasan perkebunan Kopi Gayo di Desa Gunung Suku berada pada Kuadran II, yaitu Growth Strategy (strategi pertumbuhan). Strategi alternatif Pengembangan Kawasan Perkebunan Kopi Gayo di Desa Gunung Suku sebagai agrowisata yaitu (a) Strategi SO (Strengths Opportunity), Strategi pengembangan potensi secara maksimal, Strategi pengembangan pemasaran dan promosi daya tarik wisata, Strategi pengembangan dengan bembuat paket wisata, (b) Strategi ST (Strengths Threats), Strategi pengembangan agrowisata berbasis masyarakat, Strategi Pengembangan dengan menonjolkan potensi yang berbeda dari daerah lainya, (c) Strategi WO (Weaknesses Opportunity), Strategi pengembangan SDM khususnya dibidang pariwisata, Strategi pengembangan aksesibilitas, Strategi pengembangan tempat menginap, makan minum dan toko oleh-oleh, (d) Strategi WT (Weaknesses Threats), Meningkatkan Kesadaran Masyarakat untuk menjaga dan melastarikan budaya lokal, serta munculnya banyak kompetitor, Meningkatkan kerja sama dengan seluruh Srakeholders, Meningkatkan pengembangan sumber daya manusia dibidang pariwisata. 
Penelitian ini membeberikan beberapa saran kepada berbagai pihak yaitu: (1) bagi pemerintah agar dapat memberikan dukungan dan perhatian khusus dalam pembangunan SDM khususnya di bidang pariwisata dan melakukan peningkatan kerja sama dengan seluruh stakeholders, (2) Bagi Swasta agar dapat melakukan kerja sama melalui pemerintah maupunpun kepada masyarakat langsung guna pengembangan pengetahuan dan pengalaman masyarakat, (3) bagi masyarakat agar dapat berperan aktif mencari ilmu pengetahuan dalam mengembangkan diri khsusnya dalam industri pariwisata dan membetuk POKDARWIS, dan terakhir (4) bagi peneliti akademis selanjutnya agar dapat membahas lebih mendalam mengenai strategi pemasaran daya tarik wisata desa gunung suku dan dampak kegiatan Festival Panen Kopi 2017.

\section{Ucapan Terimakasih}

Terima kasih penulis ucapkan kepada Prof. Made Sudiana Mahendra, MApp,Sc., Ph.D dan Dr. Ir. Widiastuti, MT selaku pembimbing pertama dan kedua atas bimbingan, arahan dan waktu yang diberikan. Ucapkan terimakasih juga penulis ucapkan kepada ketiga dosen penguji yaitu, Prof. Dr. I Nyoman Darma Putra, M.Litt, Prof. Dr. Ir. I G.P Wirawan, M.Sc dan Prof. Dr. Ir. Made Antara, MS yang telah banyak memberikan masukan dan arahan.

\section{DAFTAR PUSTAKA}

[1] Anonim. 2017. Laporan Akhir Penyususnan Rencana Induk Pembangunan Pariwisata Daerah Kabupaten Aceh Tengah. Dinas Pariwisata Kepemudaan Olahraga Kabupaten Aceh Tengah.

[2] Bambang, Pamulardi. 2006. Pengembangan Agrowisata Berwawasan Lingkungan (Studi Kasus Desa Wisata Tingkir)". Semarang: Universitas Diponogoro.

[3] Basuki, Sulistio. 2010. Metode Penelitian. Jakarta: Penaku.

[4] BPS. Provinsi Aceh. 2016. Jumlah Kunjungan Wisatawan. Aceh.
[5] Budiasa, I Wayan. Konsep dan Pengembangan Agrowisata di Bali. dwijen AGRO. Program Studi Agribisnis, Fakultas Pertanian, Universitas Udayana Denpasar: Vol. 2 (1)

[6] Budiasa, I Wayan. 2011. Pertanian Berkelanjutan dan Teori Permodelan. Universitas Udayana Press.

[7] Chalik, E.A. 1994. Panduan Sadar Wisata I. Kadit Bina Wisata Nusantara. Jakarta.

[8] David. F. R. 2009.Manajemen Startegis. Jakarta: Samlemba Empat.

[9] Fitria, Jayadi. 2016. Pemerintah Aceh Akan Kembangkan Agrowisata Kopi Gayo. Aceh Tengah. Rri.co.id. Radio Republik Indonesia.

[10]Freddy, Rangkuti. 2009. Analisis SWOT Teknik Membedah Kasus Reorientasi Konsep Perencanaan Startegis untuk Menghadapi Abad 21. Jakarta: PT. Gramedia Pustaka.

[11]Hammaddin. 2017. Tanoh Gayo dan Potensi Agrowisata Kopi. Aceh Tengah. Lintas Gayo, diakses http://lintasgayo.co/2017/09/26/tanohgayo-dan-potensi-agrowisata-kopi

[12] Husain E. 2006. Konsep Multifungsi untuk Revitalisasi Pertanian. Warta Penelitian dan Pengembangan Pertanian Indonesia. Vol. 28(5), pp 1-4.

[13]Moleong, Lexi j. 2004. Metodologi Penelitian: Edisis Revisi. Bandung: Remaja Rosdakarya.

[14]Palit, Ireine Graia. Talumingan, Celcius dan Rumagit, Grace A.J. 2017. Strategi Pengembangan Kawasan Agrowisata Rurukan. Jurnal Agri-Sosio Ekonomi Unsrat. Vol. 13, pp 21-34.

[15] Pratiwi, Dea. 2015. Peran Pemuda Olah Raga dan Pariwisata dalam Mengembangkan Potensi objek wisata di Dearah Kabupaten Kutai Timur. Ejournal Ilmu Pemerintahan. Fisip, Unmul. Vol 3 (2). Pp 1070-1082.

[16]Rohim, A. 2008. Analisis Stategi Pemasaran Melalui Pendekatan SWOT. Jurnal Ekonomi Manajemen dan Bisnis (EMAS). Mojokerto: Universitas Mayjen Sungkono (UNIMAS). Vol II, No 1 
[17]RPJM Kabupaten Aceh Tengah. 20122017. DISBUDPARPORA. Takengon. Aceh Tengah.

[18] Sri Endah Nurhayati. 2012. Pengembangan Agrowisata Berkelanjutan Berbasis Komunitas Di Batu, Jawa Timur". Yogyakarta: Univrsitas Gadjah Mada

[19] Yogyakarta: Universitas Gadjah Mada.

[20] Sukri, Muhammad. 2016. Hikayat Negeri Kopi. Jakarta: PT. Gramedia Widiasarana Indonesia.

[21]Sumantara Ketut. At al. 2015. Pengembangan Model Agrowisata Salak Berbasis Masyarakat di Desa Sibetan. Bakti Saraswati. Fakultas Pertanian. Denpasar: Unmas. Vol. 04. No.02.

[22] Utama. I Gusti Bagus Rai. 2016. Pengentar Industri Pariwisata Tantangan dan Peluang Bisnis Kreatif. Yogyakarta: Deepublish.

[23] Oka A. Yoety. 2016. Perencanaan dan Pengembangan Pariwisata. Cetakan ketiga. Jakarta: PT Balai Pustaka. 